\title{
Os Outros: CRiações de Joyce CAROL OATES E ALEJANDRo AmENÁBAR SOB A REGÊNCIA DE HENRY JAMES
}

\author{
The Others: Joyce Carol Oates' and \\ Alejandro Amenábar's works under the \\ conduction of Henry James
}

\section{Brunilda Tempel Reichmann*}

A crítica literária tem trabalhado nas últimas décadas com a questão da alteridade na literatura, como resultado de uma crescente consciência crítica a respeito das diferenças e peculiaridades dos povos, etnias e culturas, de posicionamentos políticos, filosóficos, sociológicos, religiosos e linguísticos. Bill Ascroft et al. (2000) enfatizam que o estudo da alteridade mudou de foco nos últimos anos do século XX: de um conceito epistêmico, no qual o outro só tinha importância na medida em que podia ser conhecido, deslocou sua ênfase para um conceito ético ou moral, no qual

\begin{abstract}
the other [...] is actually located in a political, cultural, linguistic or religious context. This is a key feature of changes in the concept of subjectivity, because whether seen in the context of ideology, psychoanalysis or discourse, the 'construction' of the subject itself can be seen to be inseparable from the construction of its others. (ASCROFT et al., 2000, p. 11-12)
\end{abstract}

O termo "alteridade", acrescenta Ascroft, apesar de ter sido usado como sinônimo de diferença, encontra solo propício na crítica pós-colonial, sendo inseparável da noção do "outro" como o colonizado e possibilita um diálogo significativo entre "outros" sob o ponto de vista cultural e racial. Simone de Beauvoir (1999) também trabalha a noção de alteridade e a caracteriza como "uma categoria fundamental do pensamento humano. Nenhuma coletividade se define nunca como Uma sem colocar imediatamente

* UNIANDRADE 
REICHMANN, B. T. Os Outros: CRiações de Joyce Carol OATES...

a Outra diante de si" (p. 11).

Entre vários outros estudiosos, Eric Landowski, em Presenças do outro (1997), ao falar sobre o "outro" coloca sua ênfase na diferença

[...] mesmo que o mundo que nos rodeia nos pareça espontaneamente um universo articulado e diferenciado, nem por isso há, entre "Nós" e o "Outro", fronteiras naturais - há apenas as demarcações que construímos, que "bricolamos" a partir das articulações perceptíveis do mundo natural. (LANDOWSKI, 1997, p. 14)

É a partir da descontextualização desse conceito e da noção de alteridade de Beauvoir que eu gostaria de adentrar o tema deste trabalho, pois ao falar sobre Uma coletividade, colocamos imediatamente a Outra diante de nós, e ao falar sobre as "articulações perceptíveis do mundo natural", Landowski nos remete involuntariamente à ideia de um mundo além do natural onde as articulações são, em sua maioria, imperceptíveis. Esta ideia surgiu ao ler o conto "Os outros", de Joyce Carol Oates, e ao assistir o filme $O s$ outros, de Alejandro Amenábar. Poder-se-ia dizer que estes "outros", tanto os do conto quanto os do filme, fogem da esfera do mundo natural, mas não à percepção de alguns participantes deste mundo. Afastamo-nos, portanto, do conceito contemporâneo de alteridade e de sua ênfase no aspecto ético ou moral e resgatamos a criação do "outro" como parte do mundo sobrenatural. o filme de Amenábar não é uma adaptação do texto de Oates, nem dialoga explicitamente com o mesmo, mas o faz de modo indireto ao referir-se aos mortos da mesma forma, como "os outros". Minha intenção é verificar como esses "outros" são trabalhados no conto de Oates e no filme de Amenábar.

\section{Momentos DE EstRAnHAmENTO No CONTO}

Joyce Carol Oates é uma escritora estadunidense com vastíssimo número de publicações: mais de quarenta romances e novelas, mais de trinta coleções de contos e cerca de dez peças, além dos ensaios críticos. $O$ conto "Os outros" é parte de uma dessas coletâneas e foi publicado em inglês com o título "The Others", em 1988. O texto é breve, recuperando criativamente, em cerca de quatro páginas, dias que antecedem a possível morte do personagem Spence, protagonista do conto. Quatro momentos tecem o fio condutor da narrativa e criam no leitor uma sensação de estranhamento: o primeiro, quando Spence, com 42 anos, vê um homem que "parecia ser da mesma idade; no entanto, aparentava ser mais velho: pele amarelada, perfil difuso como se visto através de um elemento aquoso, transparente, mas 
denso" (OATES, 2000, p. 130). No segundo momento, Spence revê a senhorita Reuters, sua professora da infância, em um guichê de correio. Há dois fatos peculiares e semelhantes em relação a esses dois momentos: no primeiro, Spence, ao voltar do escritório para a casa, toma um caminho diferente; no segundo, Spence vai a um correio que não costumava frequentar. Além desse fato de ele estar em local estranho, há a consciência, em ambos os momentos, que a pessoa que ele vê (no primeiro) e com quem fala (no segundo) já estão mortas. É um elemento surpresa para o leitor saber que Spence identificara o homem que vira durante o dia, fato que deixa claro apenas ao relatar o acontecimento a sua esposa à noite. Depois do encontro com a professora "morta", Spence "começou a vê-los com mais frequência. Os Outros - como ele os chamava" (OATES, 2000, p. 131). O terceiro momento relatado com detalhe é elaborado em forma de diálogo. Em uma determinada manhã, a esposa de Spence o vê observando a rua da janela do quarto e toca-lhe as costelas, brincando. Nesse momento, a esposa paradoxalmente compartilha da visão de Spence. Ele diz:

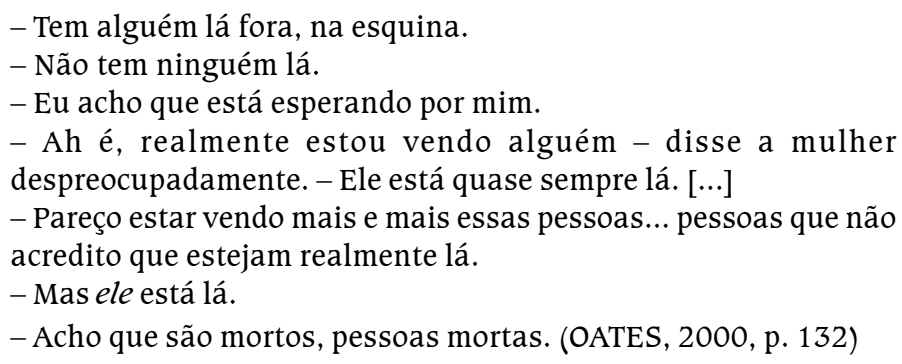

No último dos quatro momentos, Spence pega o caminho subterrâneo da estação de metrô até seu escritório, em uma manhã clara e gélida. Era um caminho que evitava, pois, além do odor fétido de algumas passagens, costumava perder-se na colmeia de túneis. Nesta manhã os túneis estavam mais cheios do que de costume e Spence deixa-se ser arrastado pela multidão até encontrar-se

\begin{abstract}
descendo para um outro túnel desconhecido, um lugar de sons mornos, monótonos e murmurantes [...] Onde estariam indo todos eles? Na mesma direção? Somente aqui e ali um indivíduo solitário, visivelmente perdido, opondo-se ao fluxo, pálido, os olhos tentando se fixar no de Spence como se esperando desesperadamente reconhecimento. (OATES, 2000, p. 133)
\end{abstract}

A autora, nesses quatro momentos, usa clichês para anunciar a morte: o aparecimento de pessoas falecidas e a imagem do caminhar por 
um túnel no momento da passagem de um estado para outro, ou seja, da vida para a morte. Esse conto foi publicado em inglês, por Oates, quando ela tinha 50 anos. Seu protagonista possivelmente encontra a morte aos 42 , quando segue com a multidão túnel adentro. Durante os acontecimentos que conduzem a narrativa, em apenas um momento Spence questiona se não estaria tendo um colapso nervoso ou algum tipo de esquizofrenia, devaneio ou alucinação - quando está à janela observando um homem na rua, ou seja, na terceira experiência. Os acontecimentos do conto são relatados de modo realista e os questionamentos demonstram que Spence não está perdendo contato com a realidade, mas que os acontecimentos estão instaurando um certo desequilíbrio na narrativa entre a realidade como era até então percebida e como passa a ser percebida. Tzvetan Todorov em Introdução à literatura fantástica (2004) diz que "O fantástico é a hesitação experimentada por um ser que só conhece as leis naturais, face a um acontecimento aparentemente sobrenatural" (p. 31). A máxima experiência do encontro com o fantástico, de acordo com o crítico, é o sentimento de hesitação no leitor, provocando um equilíbrio instável que não pode se romper, caso contrário o fantástico deixa de existir. É em $A$ construção do fantástico na narrativa (1980), de Felipe Furtado, que vamos nos aproximar de uma explicação da presença do fantástico no texto e não no leitor. Ele diz:

Uma organização dinâmica de elementos que, mutuamente combinados ao longo da obra, conduzem a uma verdadeira construção de equilíbrio difícil [...] é da rigorosa manutenção desse equilíbrio, tanto no plano da história como no do discurso, que depende a existência do fantástico na narrativa. (FURTADO, 1980, p. 15)

Para Furtado a essência do sobrenatural reside na coexistência dos mundos natural e sobrenatural na narrativa, colocando-se assim em posição diferente à do crítico russo, ao ver a hesitação do leitor apenas como um reflexo do desequilíbrio do texto.

Um texto só se inclui no fantástico quando, para além de fazer surgir a ambigüidade, a mantém ao longo da intriga, comunicandoa às suas estruturas e levando-a a refletir-se em todos os planos do discurso. [...] Longe de ser o traço distintivo do fantástico, a hesitação do destinatário intratextual da narrativa não passa de um mero reflexo dele, constituindo apenas mais uma das formas de comunicar o leitor a irresolução face aos acontecimentos e figuras evocados. (FURTADO, 1980, p. 40-41) 
Ainda segundo Furtado, o fantástico segue convenções rígidas, pois uma pretensa liberdade narratológica acarretaria em dano para a narrativa:

\begin{abstract}
Longe de resultarem da completa e desenfreada liberdade de imaginação que quase sempre procuram aparentar, a história e o discurso fantástico são, pelo contrário, objeto de calculada contenção e de forte censura interna. [...] Como toda obra intensamente invadida pelo verossímil, ela entrega-se a cada passo a um semnúmero de normas, de esquemas, de códigos previamente definidos pela mentalidade dominante da época em que foi produzida e pelos seus reflexos literários cristalizados no gênero em que se inclui. (FURTADO, 1980, p. 51-52)
\end{abstract}

\title{
Momentos Iniciais De EstRAnHAMENTO No FILME
}

As citações incluídas acima aplicam-se também ao filme The Others [OS outros], de Amenábar, que controla seu material com maestria. Com Os outros (2001), primeiro filme em língua inglesa de Amenábar, nascido no Chile em 1972 e radicado na Espanha desde a infância, o cineasta espanhol projeta-se universalmente como um dos grandes cineastas da contemporaneidade. Amenábar já havia atraído a atenção de um grande número de espectadores com seus dois primeiros longa metragens. 0 primeiro, intitulado Tese, (1996) [Thesis: morte ao vivo], é um filme de suspense e assassinato; Abre los ojos (1999) [Preso na escuridão], o segundo, é um filme que trata de assuntos polêmicos como a realidade virtual e a criogênese. O quarto filme, dirigido depois de Os outros, é a sensível produção sobre a eutanásia Mar adentro (2005) [Mar adentro], vencedor do Oscar de Melhor Filme Estrangeiro (2005), de dois prêmios no European Film Awards (2004) e de 14 prêmios no Goya em 2005. Essa breve descrição dos filmes de Amenábar deixa claro que sua preferência recai sobre assuntos polêmicos, que vão desde o suspense hitchcockiano até os limites das controvertidas tecnologia e ciência contemporâneas.

Filme com história, ambientação, atmosfera e tensão semelhantes, Os outros estabelece um diálogo intertextual com The innocents (1961) [OS inocentes], adaptação da novela de Henry James (1843-1916), The turn of the screw (1898) [A volta do parafuso]. Os dois filmes - Os inocentes e OS outros - possuem características góticas marcantes: subvertem a noção de realidade empírica ao introduzirem o elemento sobrenatural; as histórias são ambientadas em local isolado; em cada história há duas crianças com capacidade de entrar em contato com o mundo dos "outros"; as protagonistas femininas vivem situações limítrofes e seus comportamentos beiram a 
histeria; a expressão dos olhos dessas protagonistas é objeto de constante focalização. Um elemento que distanciaria os dois filmes é a conduta da governanta que, em Os inocentes, é emocionalmente instável, marcando assim o tom da narrativa, enquanto que em Os outros a governanta é uma mulher mais experiente, firme, controlada e conhecedora da situação na qual a família vive. Distanciaria os filmes, caso não coubesse à mãe o "controle" da narrativa em Os outros. Ela desempenha o papel de mulher instável e descontrolada, semelhante ao da governanta em Os inocentes, fazendo assim com que ambas as protagonistas possuam as mesmas características. Em Os outros há, no entanto, uma potencialização da subversão no que diz respeito ao suspense e ao final do filme. Essa e outras características serão mencionadas no desenvolvimento do trabalho. O prólogo ou incipit - duas cenas e oito ilustrações - insere o espectador imediatamente na diegese do filme $O S$ outros, pois a "câmera subjetiva" sugere um espectador primeiro acompanhando, com a câmera na mão, uma mulher que sobe os degraus da escada de uma maneira determinada, cortando para a segunda cena na qual os personagens estão aparentemente posando para uma foto, entre eles um ser sobrenatural; e depois, com uma vela na mão, iluminando e observando minuciosamente as ilustrações, sob o bruxulear da chama, em um ambiente envolvido pela escuridão.

\section{SUbVERSÃo PotencIALIZADA}

A leitura das "histórias de fantasmas" (expressão usada por Todorov), criadas por Henry James, sugere uma imagem complexa e de difícil captação. De 1868 a 1908, o romancista dedica-se a narrativas fantásticas: a primeira sendo De Grey: A Romance (1868) e a última The Jolly Corner (1908). A volta do parafuso (1898) permanece, no entanto, como uma das mais instigantes "onde a ambigüidade é mantida ao longo de todo o texto e onde ela representa um papel dominante" (TODOROV, 2004, p. 185). Essa manutenção da ambiguidade traz o leitor de volta ao texto repetidas vezes em uma tentativa frustrada de "resolver" o mistério que permeia a narrativa. No conto de Joyce Carol Oates "Os outros", mencionado acima, encontramos a mesma transgressão que carrega seu texto com tons do fantástico. A narrativa desenvolve clichês para a proximidade da morte e para a passagem de um estado (vida) para outro (morte), mas como em $A$ volta do parafuso, a ambiguidade permanece além do término da leitura do texto. Nelson de Oliveira (2008), colunista do Jornal de Literatura do Brasil, assim descreve a ambiguidade em Henry James

Aí está o fantástico clássico: entre o mundo real e o mundo sobrenatural. Ele se fundamenta na hesitação do narrador e do 


\begin{abstract}
leitor, que não sabem, nem têm como saber, qual seria a verdadeira explicação dos acontecimentos que vão passando diante de seus olhos. Quando as evidências parecem apontar para determinada direção - o plano de uma mente criminosa ou a loucura do protagonista ou o mundo sobrenatural - novos acontecimentos vêm mudar o rumo da história e confundir o narrador e o leitor. É o que acontece, por exemplo, no romance $A$ volta do parafuso, de Henry James, no qual até mesmo no desenlace o discurso do narrador não permite que o leitor saiba se os fantasmas existem mesmo ou se tudo não passa de alucinações da protagonista. Aí a ambigüidade jamais desaparece. (OLIVEIRA, 2008)
\end{abstract}

Ao escrever narrativas "de fantasmas", Henry James transgride as leis da realidade empírica e abre espaço para a existência de outras esferas de existência cujos habitantes não são seres "reais". Nessa arte transgressora incluímos as narrativas de Oates e de Amenábar: ambas abordam assuntos que transcendem nossa realidade empírica. Com o filme Os outros, no entanto, essa transgressão - a presença de mortos ou fantasmas - é elevada à segunda potência, pois o mistério e a existência de seres sobrenaturais sofrem um revés no final do filme, intensificando o suspense e introduzindo um elemento surpresa contundente. A crença na possibilidade da existência de fantasmas vai aos poucos tomando corpo no filme, principalmente pelo acesso da menina Anne [Alakina Mann] e da governanta, Sra. Mills [Fionnula Flanagan], aos dois mundos e posteriormente pelo acesso ao mundo dos mortos pela própria mãe, Grace [Nicole Kidman]. A grande subversão, no entanto, dá-se mais para o final do filme, quando o espectador, desestabilizado pela instabilidade emocional da protagonista, pela tensão e suspense criados pela atmosfera do filme, tem suas expectativas, não frustradas, mas novamente intensificadas ao descobrir que os protagonistas e os empregados da casa, personagens que atuaram o tempo todo como pessoas da realidade empírica, são os fantasmas do filme. $O$ espectador, nesse momento da descoberta, necessita refazer sua trajetória de leitura e restabelecer seu vínculo com a "realidade" no filme, pois esta acaba de escapar-lhe das mãos. Outras subversões e ações que criam um tom sombrio e de suspense aparecem em forma de metáfora e no obsessivo abrir e fechar de portas e cortinas. $O$ jogo entre luz e escuridão, inverte-se no filme: a luz passa a ser a mensageira da morte, pela rara doença das duas crianças - xeroderma pigmentoso ou fotossensibilidade -, e a escuridão, a possibilidade de salvação - se as crianças forem mantidas longe da luz, poderão sobreviver. A imposição da religião católica com toda gama de culpas e punições, anunciadas e infligidas pela mãe tornam a convivência, principalmente entre mãe e filha, quase insustentáveis. Existe ainda algo mais, há uma lembrança da filha que é apenas sugerida e se esclarece no final. Essa lembrança aparece na afirmação 
feita algumas vezes por Anne: "Como naquele dia". A mãe, ao tentar proteger dos filhos, intensifica o medo das crianças que sorrateiramente invade o universo do espectador que passa a reviver seus próprios medos infantis. Do início ao fim do filme, o espectador tem de lidar com esses medos, pois afinal as crianças são os seres mais suscetíveis e as grandes vítimas no filme. Esse é o fio condutor da narrativa de Amenábar, ao conceber o filme, como revelado nas Notas de Produção (DVD 2): A ideia de medos da infância se tornando realidade tem fascinado
por muito tempo o diretor Alejandro Amenábar, que já é considerado
um prodígio dos thrillers que desafiam a realidade. Sobre Os outros,
diz que "sempre quis fazer um filme repleto de corredores longos
e escuros, um tributo a estes seres sempre mascarados que
assombram dos meus pesadelos de infância."

"Minha infância foi povoada por diversos medos - medo do escuro, medo de portas entreabertas, medo de armários, e de uma maneira mais geral, medo de qualquer coisa que pudesse esconder alguém ou alguma coisa," recorda. "Sendo assim, não é nenhuma surpresa o fato de eu ser avidamente dedicado ao cinema do oculto."

"Sempre me pergunto," prossegue, "por que temos tanto prazer em sentir medo. E acredito em parte que seja porque a experiência do mundo é muito intensa, mas ao mesmo tempo sabemos que estamos seguros no nosso lado da tela. E o quanto mais esta segurança for questionada, mais assustador será o filme." (THE OTHERS, DVD2, 2001)

A percepção que estamos em um mundo que dá abertura a outros mundos começa a delinear-se no filme de modo muito sutil e sem efeitos artificiais ou superficiais. Como também mencionado nas Notas de Produção dos Extras:

Amenábar sabia desde o início que o encanto de Os outros só poderia ser criado através de uma forte ênfase em clima e psicologia, e não através de efeitos superficiais. "Acredito que neste tipo de filme é perigosamente fácil exagerar nos efeitos especiais e transformar os sustos desejados em mera repulsa," observa. "Para mim, deixar algo a cargo da imaginação é a essência do horror real. o horror mexe com as ansiedades, obsessões e paranóias latentes em nossas consciências. Desperte esses sentimentos primais e você transportará o espectador de volta aos cantos mais escuros dos medos de infância - de volta para aquele arrepio na espinha que só pode ser descrito como terrivelmente maravilhoso." (THE OTHERS, DVD2, 2001) 
E este foi o objetivo de Amenábar em Os outros. Ele também queria apresentar uma nova visão de casa mal-assombrada, com uma surpreendente reviravolta no clímax que permanece por um longo tempo em nossa imaginação. "Muitas histórias de terror são sobre pecado - a ideia de que deve-se [sic] purgar a maldição de uma casa ou pessoa para que os fantasmas desapareçam e o bem triunfe," observa. "Mas com Os outros procurei abordar o assunto de outro ponto de vista. Os personagens não são heróis nem vilões, mas apenas pessoas comuns tentando compreender uma situação que desafia tudo aquilo em que acreditam."

\section{O PRólogo ou INCIPIT do FILME}

O prólogo ou incipit do filme, como já mencionado, contém duas cenas e uma série de oito ilustrações filmadas. A primeira cena, com uma montagem que remete a Eisenstein, estabelece o conflito: linhas verticais cortam um fundo marcado por fortes linhas horizontais. Os degraus da escada, definidos por marcante luz e sombra, são cortados pelas pernas de uma mulher, com vestido escuro e austero e sapatos pretos amarrados com tacões pesados, que sobe a escada. O som dos passos assemelha-se a estampidos e carrega o espectador escada acima, quando uma nova cena nos introduz a um mundo onde seres aparentemente normais e um ser "estranho" encaram a câmara. A câmera está supostamente sendo carregada pelo espectador, e os serem estão estáticos como se estivessem posando para uma foto, estabelecendo assim um diálogo com as fotos dos mortos posteriormente encontradas na mansão. Essas duas cenas curtas nos remetem a um dos temas do filme: a existência de mundos paralelos - o natural e o sobrenatural. Logo após essas tomadas, tendo como fundo uma tela totalmente escura, escuta-se uma breve história sobre a criação do mundo, baseada no relato Bíblico, narrada por voz de mulher em voice-over. Ela diz:

Muito bem, crianças, estão sentadas confortavelmente? Então vou começar. "Esta história começou a milhares de anos, mas acabou em sete dias. Há muito tempo, nenhuma das coisas que vemos agora... o sol, a lua, as estrelas, a terra, os animais e as plantas... nada disso existia. Só Deus existia e só Ele poderia tê-las criado. E Ele as criou." (THE OTHERS, DVD2, 2001)

À medida que a narradora conta essa história, a ilustração da criação do mundo com o sol no centro, vai sendo filmada rapidamente, tendo como iluminação a luz de vela, como se esta estivesse também sendo segurada pelo espectador. Eliminando-se o espaço onde a luz incide, o resto é escuridão na tela. A seguir mais sete ilustrações, estáticas, todas em PB, 
com traços simples e ângulos normais, são filmadas rapidamente e compõem o pano de fundo do incipit do filme.

A noção de incipit é elaborada por João Manuel dos Santos Cunha, no artigo "Da palavra-imagem à imagem-palavra"1, no qual aproxima o conceito de prólogo literário - ou incipit - à noção de paratexto de Gerard Genette. Ele diz:

No quadro dessa articulação teórica, seqüências iniciais de um filme - mesmo enquanto são passadas as informações sobre a "ficha técnica" sob a forma de "apresentação de créditos" - apresentam já as primeiras informações diegéticas. A abertura de filmes, assim, pode ser lida nos mesmos termos de um incipit literário, ou ao que Genette (1982, p. 150) denomina paratexto: “[...] toda espécie de pré ou pós-liminar, constituindo-se como um discurso produzido a propósito do texto que segue ou que precede o texto propriamente dito". (CUNHA, 2007)

Após as duas cenas iniciais, as oito ilustrações ${ }^{2}$ contêm os seguintes elementos: primeira, mostra a criação do mundo, com o sol e a iluminação no centro e sombra no contorno; a iluminação passa para o lado direito da tela onde vemos animais, seguido de travelling da câmera para o lado esquerdo no qual se vê um menino e uma menina de mãos dadas, de costas, observando a criação. Segunda, tomada com início no primeiro degrau da escada, seguida de movimento ascendente, acompanhado a curvatura da escada onde se encontram duas crianças sentadas lado a lado nos degraus; elas observam o que acontece abaixo, por entre os balaústres. Terceira, um menino brincando no chão ao lado de uma senhora com um livro no colo, que parece conversar com uma menina à sua direita. Quarta, mão direita segurando um castiçal tosco e uma vela acesa, mão esquerda introduz uma chave para abrir uma fechadura. Quinta, escada, menina sentada no meio da escada apontando para um espaço no topo à sua direita, mulher de costas, encarando a menina. Sexta, vulto alongado na janela estendendo sua mão para o menino com expressão apavorada deitado na cama com o rosto sobre o travesseiro. Sétima, mão segurando a guia da marionete - um menino de pele clara e cabelos escuros com a com cabeça caída para o lado e asas de anjo. Oitava, a mansão e seu reflexo no lago à frente. Essa última ilustração transforma-se na primeira vista panorâmica da mansão, onde

\footnotetext{
1 João Manuel dos Santos Cunha, "Da palavra-imagem à imagem-palavra: análise do incipit fílmico de Lavoura arcaica". Revista Brasileira de Literatura Comparada, n. 10, 2007, p. 98

2 Poder-se-ia apreender-se as ilustrações como parte do storyboard do filme - algumas transformadas em cenas e outras descartadas pelo diretor. No entanto, apesar de a maioria das ilustrações mostrarem traços simples e até inacabados, outras, como a ilustração da escada com as duas crianças, parecem dizer que as ilustrações não são parte de um storyboard pela minúcia de detalhes do desenho.
} 
moram Grace, Anne, e Nicholas [James Bentley], o filho. Lê-se na tela:Jersey, the Channel Islands, 1945.

Há uma série de detalhes importantes a serem observados nessas ilustrações. Com relação ao movimento da câmera, apenas a primeira e última iniciam a filmagem com o objeto centrado, seguido de zoom-out ou distanciamento entre a câmera e o objeto. Nas outras ilustrações, o movimento é sempre em diagonal. o travelling em diagonal cria uma sensação de instabilidade e desequilíbrio, elementos característicos do fantástico. A luz instável ou bruxuleante da vela intensifica a instauração do mistério e do desejo de desvendá-lo, sentimento que prevalecerá até o final do filme. Já neste primeiro momento, o uso da luz da vela abre espaço para a já mencionada inversão ou subversão trabalhada no filme: a luz é percebida como um algoz ("a luz mata", diz Amenábar a um dos colegas de trabalho) e a escuridão, como uma possibilidade de salvação. A luz que vemos é um inconstante bruxulear da chama da vela, retirando a possibilidade de observar-se a realidade com clareza.

O texto em voice-over que acompanha as ilustrações - a história da criação do mundo por Deus - marca de forma contundente a religiosidade que será uma das tônicas do filme. O uso da voice-over, tendo no início a escuridão como fundo, e a primeira ilustração complementam-se, pois a história, a escuridão e a ilustração são tematicamente ligadas. No entanto, elas criam um discurso misto e não sincrético (HOECK apud ARBEX, 2006, p. 179), pois a existência de uma não é dependente da existência da outra. Elas se complementam apenas, complementação que se desfaz assim que os créditos começam a aparecer e têm como pano de fundo as outras sete ilustrações. A partir desse momento não há mais relação entre o texto e as ilustrações. As ilustrações irão antecipar, no entanto, algumas tomadas do filme ou instaurar o universo de medos infantis.

Outro detalhe a ser observado: a relação entre som e imagem produz uma resposta no espectador cuja língua é o inglês. Para o espectador brasileiro, a relação dá-se entre o áudio, a escrita (legenda) e a ilustração como pano de fundo. Mas tanto na versão inglesa como na versão em língua portuguesa podemos dizer que, durante a narrativa da história da criação do mundo, há primazia do "texto" sobre a imagem. A história narrada chega a ser violentamente incontestável. Essa história poderia, no entanto, ser narrada sem a ilustração como fundo sem perdas consideráveis. O mesmo não se pode dizer da história em si. Ela possui uma força e "determinação" em sua simplicidade que não deixa margem de dúvida quanto ao rigor relativo a assuntos religiosos explorados no filme. As sete ilustrações seguintes fornecem ao leitor uma possibilidade de entrar no mundo infantil, onde livros de histórias com ilustrações semelhantes são frequentes e os 
vazios têm que ser preenchidos pela imaginação contaminada pelo pavor criado pela escuridão e pelo desconhecido.

Há alguns pontos em comum em algumas ilustrações: quando a ilustração inclui a escada da casa, o movimento da câmera é sempre ascendente: na segunda ilustração as crianças observam, sentadas na metade da escada, o que está acontecendo no andar térreo; na quinta, a menina aponta para o alto enquanto parece revelar alguma coisa para a mulher à sua frente, de costas para a câmera. Esses movimentos ascendentes vêm ao encontro de outras posições de agressão por seres que estão acima (fantasmas) e abaixo das crianças (a mãe). Nicholas, com cerca de sete anos, é o personagem que mais teme os acontecimentos, até porque ele é o personagem a quem a irmã Anne relata as aparições de Victor, um suposto fantasma. As "aparições" no filme são vistas no início apenas por Anne e ela é severamente punida pela mãe por "fantasiar" - tem de ficar três dias sentada na escada, lendo a Bíblia, por ter revelado à mãe a existência de Victor. A quinta ilustração encontra correspondência no filme, quando, após ouvir barulhos inexplicáveis no andar de cima, a mãe pergunta à filha onde estariam os "intrusos". Anne aponta o sótão para a mãe e depois lhe mostra um desenho com os "intrusos", anotado ao lado de cada um o número de vezes que os vira. A mãe fica atônita ao descobrir esse "fato" e parece acreditar na filha. Pega uma arma e vasculha o sótão, e mais tarde pede perdão à filha enquanto esta finge dormir. Nicholas, o personagem mais jovem, sensível e dependente, aparece nas ilustrações sempre em posição inferior aos outros seres, quer seja a governanta ou a sombra do fantasma que tenta agarrá-lo através da janela. Na terceira ilustração, um menino, possivelmente Nicholas, está ajoelhado, absorto, brincando de trenzinho no chão ao lado da Sra. Mills e da irmã. Na sexta, o menino está deitado na cama, de costas para a janela, em pavor total com a aparição de um ser não identificado que estende a mão para agarrá-lo. Nicholas imagina em pavor o que jaz atrás de si, atitude típica do mundo infantil, no qual as crianças temem o que lhes escapa ao olhar.

A quarta ilustração antecipa um momento de grande suspense na narrativa fílmica. Todos da casa estão proibidos de tocar nas teclas do piano devido à enxaqueca de Grace, a mãe. À noite, já pronta para dormir, Grace escuta o som do piano, pega uma vela e uma espingarda e introduz a chave na fechadura da sala de música, destrancando a porta, mas depois de abrila não vê ninguém nem escuta qualquer som. Ela então fecha o piano à chave e coloca a mesma no bolso do seu penhoar, em uma tentativa de impossibilitar que alguém toque nas teclas do piano. Assim que se afasta da sala, não é apenas jogada no chão pela batida na porta, como ao entrar novamente na sala vê o piano aberto. Com essas experiências, o suspense e 
mistério vão se intensificando, pois Grace, religiosa e avessa a "fantasias", expressão que usa para qualificar as visões de Anne, parece estar realmente acreditando que a casa está sendo invadida por "intrusos" que ela não consegue ver. No entanto, parece que Grace ainda assim não acredita na existência de seres sobrenaturais - para ela a espingarda resolveria a invasão. Como ela afirma, conseguira manter os nazistas fora de sua propriedade durante a guerra, não permitirá que outros intrusos tenham acesso à mansão.

A penúltima ilustração é uma das mais intrigantes da abertura, pois há uma marionete - um menino com asas de anjo, com a cabeça caída para o lado, semelhante a um enforcado -, como se a sugerir que a preservação da inocência não é possível neste mundo onde as crianças são marionetes nas mãos dos adultos ou na mão do Criador. Marionetes são bastante enfatizados no filme também, pois há um teatro de marionetes no quarto das crianças. Além disso, em um momento crítico do filme, quando Grace retorna, depois de ter permitido que Anne ficasse um pouco mais de tempo com o vestido branco da primeira comunhão que está provando, a mãe nota que a mão que segura a guia das marionetes é de uma velha. Ao aproximar-se, vê um estranho rosto envelhecido, entra em crise histérica e sacode a velha pelos ombros, chamando por sua filha. Grace é trazida de volta a realidade pelos gritos de Anne que diz que a mãe a está machucando. Este incidente intensifica o rancor que Anne sente pela mãe, pois ela sabe que sua mãe praticara um ato violento "naquele dia". Essas relações, no entanto, só poderão ser estabelecidas após assistir o filme uma segunda vez. As ilustrações podem passar despercebidas ao espectador na primeira vez que assiste o filme, mas possivelmente elas já tenham atingido o que parece ser seu objetivo maior: fazê-lo adentrar o mundo dos medos e pavores infantis.

o diálogo entre as ilustrações e o filme não se revela fundamental para a compreensão ou intensificação dos momentos de tensão do filme. $\mathrm{Na}$ verdade, o uso das ilustrações na abertura do filme, resultado de uma relação multimidial, apesar de estabelecer um diálogo com o filme, não é indispensável para sua compreensão. Em alguns momentos sente-se que a inclusão das ilustrações, com o texto em voice-over, a música e os créditos (acrescente-se as legendas em português quando a história da criação do mundo está sendo narrada) transforma a tela em espaço poluído e almeja-se que Amenábar tivesse optado por um fundo escuro. As ilustrações, além de poluírem a tela, parecem dispersar a atenção do espectador que, para observar as figuras, não poderá deter-se nos créditos iniciais ou vice-versa; no entanto, é durante a projeção das ilustrações que o espectador é cooptado para um universo diferente do universo da realidade empírica ou para o universo dos "outros". 
REICHMANN, B. T. Os Outros: CRiações de Joyce Carol OATES...

\section{CONSIDERAÇÕES FinAIS}

Dos diálogos implícitos e explícitos entre os textos, parece prevalecer primeiro um alerta para o olhar. Na tentativa de acompanharmos um caminho de sons "mornos, monótonos e murmurantes" e personagens perplexos ou de traçarmos um trajeto iluminado pela chama trêmula da vela, Oates e Amenábar possivelmente estejam querendo alertar o leitor ou espectador sobre a importância desse olhar e sobre as articulações quase imperceptíveis do mundo sobrenatural. Este mundo permanece paralelo, portanto "outro" em relação ao mundo no qual vivemos. Aliás, o próprio trajeto da realidade empírica é mal iluminado, impossibilitando uma visão nítida e segura do que está à nossa frente. Portanto, pouco nos é dado conhecer além de uma realidade "mal iluminada". Como segundo e talvez o ponto mais importante no filme, permanece a intenção de conduzir o espectador de volta ao universo dos medos e pavores infantis, preparando-o assim emocionalmente para adentrar o universo de suspense. Instala-se um grande desequilíbrio, como nas "histórias de fantasmas" de Henry James, não apenas nas narrativas como quer Furtado, mas nos leitores e espectadores, como quer Todorov, que adicionado ao desconforto e estranhamento paralisa o leitor e o espectador. Narrativas ou ilustrações de um universo sobrenatural que lembram os textos e as figuras dos livros infantis evocam uma pletora de medos e apreensões no espectador ao levá-lo de volta ao passado e questionar constantemente a evidência de sua realidade empírica.

\section{RESUMO}

Este trabalho tece comentários sobre o estranhamento no conto "Os outros", de Joyce Carol Oates, e no filme Os outros, de Alejandro Amenábar, sob a regência de Henry James. Com um controle total sobre as narrativas, tanto Oates como Amenábar constroem universos ficcionais surpreendentes. A narrativa de Oates tem como fio condutor quatro momentos da vida do protagonista; a narrativa de Amenábar estabelece um diálogo implícito com o texto de Oates e um diálogo explícito com o filme The Innnocents, baseado na novela The Turn of the Screw, de Henry James. O filme Os outros apresenta um final surpreendentemente chocante, no qual o espectador vê-se diante de uma situação inusitada que o faz retornar mentalmente ao início do filme e refazer a trajetória narrativa. A pergunta que paira é: "Afinal, quem são 'os outros'”? Para respondermos a essa pergunta, utilizaremos alguns aspectos 
de teoria sobre o fantástico de Tzvetan Todorov e de Felipe Furtado. Ambas as narrativas subvertem a realidade empírica ao incluir elementos de um mundo sobrenatural. Amenábar potencializa essa subversão. O filme, assim como o conto, joga com nossa percepção da realidade e nosso relacionamento com um mundo que só pode ser apreendido pela imaginação ao suspendermos nossa descrença diante da inusitada "realidade" criada pelas narrativas ficcional e fílmica.

Palavras-chave: Os outros; A subversão da realidade; O fantástico.

\begin{abstract}
This paper comments on the sensation of estrangement while reading the short story "The Others", by Joyce Carol Oates, and watching the film The Others, by Alejandro Amenábar, both texts written under the regency of Henry James. Having total control over the narratives, Oates as well as Amenábar create surprising fictional universes. Oates's narrative has as its conducting thread four moments of the protagonist's life; Amenábar's narrative establishes an implicit dialogue with Oates's text and an explicit dialogue with the film The innocents, adapted from the Turn of the Screw. The film The Others also presents a surprisingly chocking ending, in which the spectator sees himself in an unknown situation which makes him go back mentally to the beginning of the film to remake the narrative thread. The question that remains is: Who are the others? To answer this question, we will use some aspects of Tzvetan Todorov's and Felipe Furtado's theories about the fantastic. The narratives subvert empirical reality when they include elements from the supernatural world. Amenábar potentializes this subversion. The film as well as the short story plays with our perception of reality e our relationship with the world which can only to be apprehended by imagination, while we suspend our disbelief in face of the unbelievable "realities" created by the fictional and filmic narratives.
\end{abstract}

Key words: The others; Subversion of reality; The fantastic.

\title{
REFERÊNCIAS
}

ARBEX, Márcia (Org.). Poéticas do visível: ensaios sobre a escrita e a imagem. Belo Horizonte: Faculdade de Letras, Universidade Federal de Minas Gerais, 2006.

ASHCROFT, Bill, GRIFFITHS, Gareth e TIFFINS, Helen. Post-Colonial Studies. The Key Concepts. London: Routledge, 2000. 
Reichmann, B. T. Os Outros: Criações de Joyce Carol OATES...

BEAUVOIR, Simone. O segundo sexo. Rio de Janeiro: Nova Fronteira, 1999.

CLÜVER, Claus. Estudos Interartes: Introdução Crítica. Floresta Encantada: Novos Caminhos da Literatura Comparada. Ed. Helena Buescu, João Ferreira Duarte, e Manuel Gusmão. Lisboa: Publicações Dom Quixote, 2001.

CUNHA, João Manuel dos Santos, "Da palavra-imagem à imagem-palavra: análise do incipit fílmico de Lavoura arcaica”. Revista Brasileira de Literatura Comparada, n. 10, p. 95-125, 2007.

FURTADO, Felipe. A construção do fantástico na narrativa. Lisboa: Horizonte, 1980.

HOEK, Leo H. A transposição intersemiótica: por uma classificação pragmática. Trad. Márcia Arbex. In: ARBEX, Márcia (Org.). Poéticas do visível: ensaios sobre a escrita e a imagem. BH: Faculdade de Letras, Universidade Federal de Minas Gerais, 2006.

INNOCENTS the. Direção de Jack Clayton. Twentieth Century Fox Film Corporation, 1961.

JAMES, Henry. A volta do parafuso. Trad. Francisco Carlos Lopes. São Paulo : Editora Landmark, 2004.

LANDOWSKI, Eric. Presenças do outro. São Paulo: Editora Perspectiva, 1997.

OATES, Joyce Carol. Os outros. Tradução Liana Leão. In: REICHMANN, Brunilda T. (Org.). Contos dos anos 80 e 90 traduzidos do inglês. Curitiba: Editora Beatrice, 2000, p. 130-133.

OLIVEIRA, Nelson. Fantasmas, fantoches, fantasias. Disponível em: http://rascunho.rpc.com.br/index.php? ras $=$ secao.php\& modelo $=2 \&$ secao $=3 \&$ lista $=$ $1 \&$ subsecao $=10 \&$ ordem $=1082 \&$ semlimite $=$ todos. Acesso em: 07/06/2008.

OTHERS the. Direção de Alejandro Amenábar. Miramax Internacional/Dimension Films, 2001. DVD.

TODOROV, Tzvetan. Introdução à literatura fantástica. São Paulo: Perspectiva, 2004.

Submetido em: 29/09/2008

Aceito em: 10/08/2009 